\title{
A Study on the Collision Avoidance Supporting Model in Coastal Area
}

\author{
Chang-Je Kim* \\ Division of Navigation Convergence Studies \\ Korea Maritime and Ocean University \\ Busan, South Korea
}

\begin{abstract}
- even though many ships have recently tried to prevent collisions by utilizing alarm functions of equipment such as radar and ais, that equipment lacked the functions of identifying collision-risk vessels and especially did not provide information on the avoidance course. Therefore, this study aims to design a newly developed collision avoidance support model based on the collision risk zone assessment method targeting mainly on small-sized ships that caused most of the collision accidents in coastal water area due to human errors. In addition, this study analyzed the collision risk of various scenarios according to the navigation relationships and speed conditions among plural ships. As a result, the model proposed in this study expressed collision risk and avoidance angle suited to the navigation situations and therefore, will be applied to build the maneuvering model of autonomous ships.
\end{abstract}

Keywords: Collision avoidance support model, Coastal water area

\section{Introduction}

According to statistics from the Korea Maritime Safety Tribunal, among marine accidents that have occurred in the last 5 years, collision accidents accounted for the largest proportion at about $10 \%$, excluding engine damage and float winding. In addition, when the collision accident is classified by type of vessel, the proportion of fishing vessels is the highest at about $63 \%$. About $46 \%$ of these collisions occurred between fishing boats and fishing boats, most frequently on small vessels of less than 20 tons (KMST, 2019). Such frequent accidents were due to the highest percentage of fishing boats sailing along the coast, and the occurrence of the accident itself was largely due to the operational characteristics of a fishing vessel such as poor working environment, fatigue accumulation due to lack of duty personnel, and lack of attention to the safety. Also, according to Jung (2014), the captain is on the duty of watch alone in most small vessels engaged in fishing near the coast, which increases the possibility of collision due to fatigue and drowsy navigation.

About $95 \%$ of collision accidents are caused by operational errors, including recognition failures, judgment failures, and action failures, and the rest are caused by uncontrollable factors such as mechanical defects and extremely bad weather (KMST, 2019). This is attributed to the emphasis on improving the performance and functionality of the machine rather than human error-related reviews in the development of machines that make up a system. Although the reliability of mechanical elements has been greatly improved by the advancement of science and technology, countermeasures against human error have not progressed much, which has become a major factor in causing accidents.

Therefore, measures should be taken to reduce or prevent human error by enhancing human reliability. In the case of ships, there are cases where the operator uses an alarm system to prevent collisions by setting the radar or AIS (Automatic Identification System) Guard Zone and Closest Point of Approach Alarm functions. However, identified vessels also contain a significant number of safe passage vessels and do not provide any risk of collision. In the case of ships, operators often set up radar or Automatic Identification System guard zones and Closest Point of Approach alarm functions to prevent collisions. However, among the identified vessels, not only collision risk vessels but also vessels passing safely are included, and since these alarms do not provide information on the route to be navigated, the effect of preventing collision risk is somewhat insufficient. Therefore, it is necessary to develop a support device that not only identifies the collision risk vessel and recognizes its approach but also recommends the avoidance course of the vessel, and research to prevent such human error should be further advanced.

The authors have been studying ways to prevent collisions with fixed structures (Kim et al., 2017, Kim et al., 2017, Kim and Kim, 2018) that can be encountered during navigation to secure safe navigation. One area of existing research is to evaluate the degree of danger to operators as ships approach fixed structures around them, such as breakwaters and islands, and to apply it to navigational safety. This study quantified the risk of collision by ship operators as the ship approaches the 
fixed structure, but there is a limit to applying the results to the avoidance of the collision risk ship because it does not provide a safe route. Furthermore, research by Kijima and Fukukawa (2001) and Son et al. (2009) quantified the risk of collision by fuzzy theory, but this also did not provide information on the safe route.

Therefore, a subsequent study (Kim et al, 2019) focused on a safe route and presented a collision avoidance support model that can alter a small and medium-sized vessel to the right under the Maritime Safety Act without colliding with moving structures such as ships at sea. In this model, we defined a Collision Avoidance Level (CAL) that quantifies the risk of collision and evaluated the CAL values across 80 degrees on each side of the basis of the course of the ship, providing a safe route in compliance with the Maritime Safety Act. Furthermore, the CAL was able to clearly identify dangerous situations because of the application of algorithms that can provide information regarding increasing or decreasing the collision risk with the ship's approach.

However, small fishing boats tend to take collision-avoidance action at a closer range than merchant vessels due to the characteristics of fishing operations and excellent maneuverability. Since the existing collision avoidance support model reflects the characteristics of small and medium-sized merchant ships, it has limitations to apply the model directly to small ships such as coastal fishing boats and inland ships.

Therefore, this study examines the avoidance support model for small fishing vessels that can prevent human error by identifying the possibility of collision with other ships and providing collision avoidance routes.

\section{Methods}

\subsection{Collision accident due to human error}

A recognition failure occurs when it is not aware of the other ship's existence or is recognized in close proximity to the collision, and judge failure occurs when the other ship is misjudged to pass or avoid safely, and the control failure occurs due to inadequate steering or poor equipment operation. The process of a collision accident can be illustrated as shown in FIGURE 2.

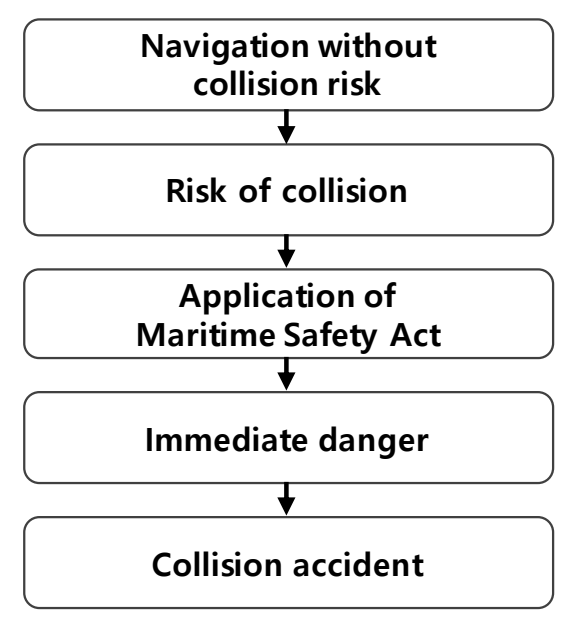

Figure 1: process of collision accident

In general, recognition, judgment, and control should be made prior to navigation to avoid collision accidents. The probability of a collision due to human error in the process of a collision in FIGURE 1 is as shown in FIGURE 2. 


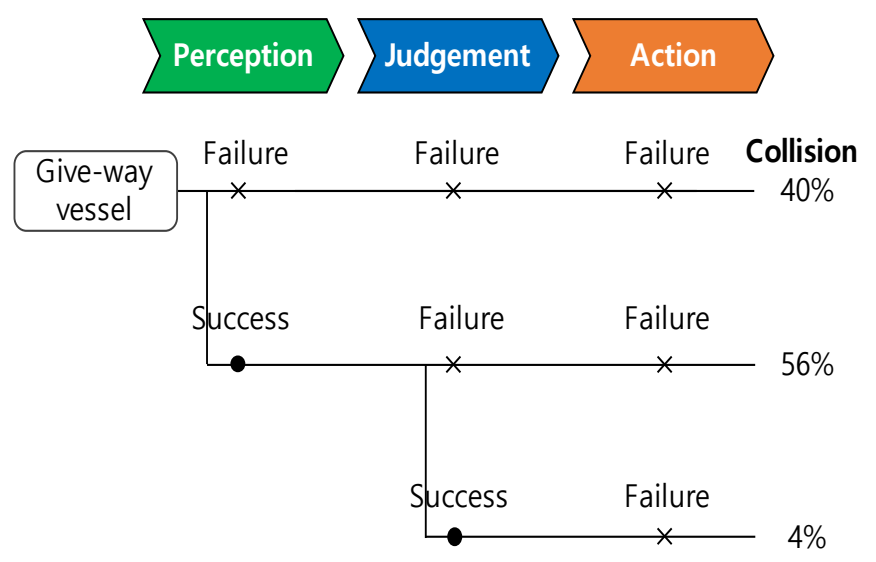

Figure 2: the process of collision caused by human errors

In FIGURE 2, the proportion of collision accidents caused by recognition failure is about $40 \%$, and it includes the consequences of colliding with the opponent ship in which one cannot avoid due to a close-quarter situation (24\%). About $56 \%$ of crash accidents are due to failure to judge whether the opponent will pass or escape safely. Therefore, it can be seen that approximately $96 \%$ of collisions are caused by failure of recognition or judgment (Arimura et al., 1992).

Meanwhile, according to Jung (2014), the proportion of collisions without recognition of the opponent ship was $28 \%$, and the proportion of accidents that was recognized just before the collision, a close-quarter situation, was $28 \%$. Although the results of the two studies are slightly different, it can be seen that recognition failure accounts for a large proportion of collision accidents at sea. In order to prevent such human error, it would be effective to get help from reliable devices such as advanced equipment. In other words, an alternative device is required which giving an alarm that notifies the approach of a vessel with a risk of collision to prevent failure of recognition and providing education or training that enhances the ability to link the machine area with the human area to prevent failure of judgment. In addition, there is a need for an alternative device to prevent control failure that can automatically control the ship without involving the operator in case the distance from the opponent is too close that there is insufficient time.

On the other hand, the development of alternative devices requires determination to what extent safety and economics should be met. In addition, to ensure safety, intrinsic safety measures that act toward safety should be pursued in all cases, but in some cases, control safety measures are preferred due to economic or technical problems.

\section{2 collision avoidance characteristics of small fishing boats}

Matsumoto (2017) analyzed the passing distance between fishing boats and non-fishing vessels in the Akashi Strait, where ship traffic is heavy, using 14 vessels such as fishing trawlers and pair trawlers of 10 tons or less. The results are summarized in Table 1.

Referring to TABLE 1, the passing distance of other ships can be regarded as 0.3 miles (about 556 meters) regardless of the operation and speed, except for the stern direction of small fishing boats. Small fishing boats sail at a speed of less than 2 knots engaged in fishing and 18 knots during non-operation. The passing distance in the stern direction according to the fishing operation is 0.33 miles (about 611 meters) and 0.34 miles (about 630 meters) respectively, slightly larger than other directions due to the fishing net, but they are simply assumed as 0.3 miles to balance with the other directions. 
Table 1: average passing distance according to the position of the opponent ship. The unit in the talbe is nautical mile.

\begin{tabular}{c|c|c}
\hline $\begin{array}{c}\text { Position of the } \\
\text { opponent ship }\end{array}$ & $\begin{array}{c}\text { Fishing } \\
\text { operation }\end{array}$ & $\begin{array}{c}\text { Non-fishing } \\
\text { operation }\end{array}$ \\
\hline Forward & 0.31 & 0.31 \\
\hline Starboard bow & 0.29 & 0.29 \\
\hline Starboard abeam & 0.30 & 0.29 \\
\hline Starboard quarter & 0.31 & 0.31 \\
\hline Aft & 0.33 & 0.34 \\
\hline Port quarter & 0.30 & 0.31 \\
\hline Port abeam & 0.29 & 0.30 \\
\hline Port bow & 0.31 & 0.30 \\
\hline
\end{tabular}

Since the fishing boat has excellent maneuverability except while dragging a net, it can avoid other ships at close range in situations where a safe distance can be secured. However, as shown in TABLE 1, other ships are not allowed to approach within 0.3 miles of the fishing vessel, and this area is called the collision risk zone.

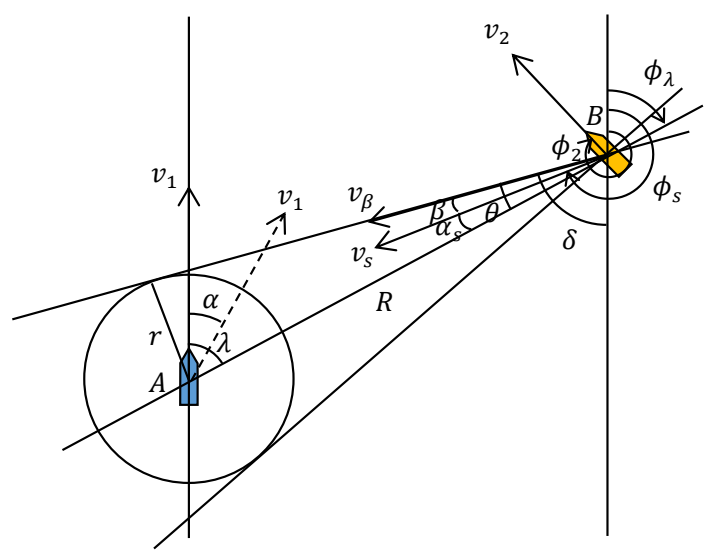

Figure 3: vector indications according to the position of two ships

In the FIGURE 3, the speed of the small ship A is $v_{1}$, the true course is 000 degree, the collision risk zone is the area of radius $r$, and the opponent ship B has the speed $v_{2}$, the true course $\phi_{2}$, the relative speed $v_{s}$, and the relative course $\phi_{s}$. In addition, $(x, y)$ is an orthogonal coordinate system, the center of the own ship is located at the origin of the coordinates, the $y$ axis is the navigation course direction of the own ship, that is, the progress direction of the own ship is the $(+)$ direction of the $\mathrm{y}$ axis, and the starboard direction of the own ship perpendicular to that $\mathrm{y}$ axis is the $(+)$ direction of the $\mathrm{x}$ axis. If the opponent vessel approaches into the collision risk zone of small ship A, changing the course of the small ship by $\alpha$ to allow the opponent to proceed out of the zone results in the relative speed of it by $v_{\beta}$ and the relative course by $\beta$, preventing the opponent from invading the area. To obtain $\alpha$, first obtain an angle $\theta$ that prevents the opponent ship from invading the collision risk zone from the following expression:

$$
\theta=\sin ^{-1}\left(\frac{r}{R}\right)
$$


Here, $R$ is the distance between the two ships. In the figure, $\phi_{\lambda}$ is the relative angle of the other ship, $\alpha_{s}$ is the angle between the straight line connecting the small ship and the other ship and the relative speed $\left(v_{s}\right)$ direction of the other ship, and $\delta\left(\phi_{s}+\beta-\pi\right)$ is explained later. In the case where the small ship is a give-way vessel, that is, in the range of $\phi_{\lambda}+\pi-$ $\theta \leq \phi_{s} \leq \phi_{\lambda}+\pi+\theta$, the following equation applies:

$$
\begin{aligned}
& \beta=\theta-\alpha_{s}\left(\phi_{s} \geq \phi_{\lambda}+\pi\right) \\
& \beta=\theta+\alpha_{s}\left(\phi_{s}<\phi_{\lambda}+\pi\right)
\end{aligned}
$$

On the other hand, the small ship that is a give-way vessel changes its course by $\alpha$ to the right in compliance with the International Regulations for Preventing Collisions at Sea (International Maritime Organization 1972) so that the relative change of the course of the opposing ship occurs by $\beta$. The following formula is used to obtain the approaching speed $v_{\beta}$ that approaches the tangent to the collision risk zone.

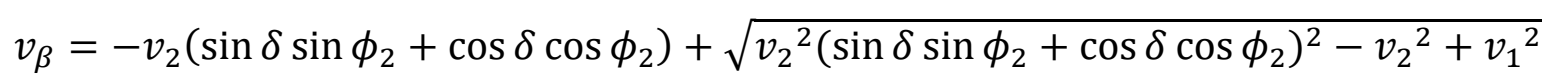

Here, $\delta=\phi_{s}+\beta-\pi$. In addition, the collision avoidance course $(\alpha)$ of a small ship that blocks the approach of the other ship to the collision risk zone can be obtained from the following equation.

$$
\alpha=\sin ^{-1}\left(\frac{v_{\beta} \sin \delta+v_{2} \cos \phi_{2}}{v_{1}}\right)
$$

\section{3 empirical model of collision prevention for small fishing boats}

Under Articles 71 [Overtaking], Article 72 [Head-on Situation], and Article 73 [Crossing Situation] of the Korean Maritime Safety Act, the obligation of a give-way and stand-on vessel between two power-driven vessels are determined by a relative positional relationship, regardless of the size of the vessel. Therefore, a small fishing vessel also has a navigation relationship on an equal right with other vessels. In addition, the timing of determination of the risk of collision varies due to the size of the ship, the maneuverability, the surrounding circumstances, etc., and has a property of being determined by the operator's subjective judgment. In particular, small fishing boats tend to take action when other ships are close.

When a vessel notifies the existence of its own ship to a small fishing vessel, it is usually used by a whistle or a call by VHF. Air horns may not be heard at all depending on the direction of the wind, and there are few ships equipped with VHF for small fishing boats, or it is often difficult to answer calls in English from foreign ships. Although these two methods are widely used on ships, they may not be effective in some circumstances, and they may cause a dangerous situation by focusing on an uncertain sound or voice leading to the neglect of navigational safety. Therefore, it is desirable to secure the safety of navigation by means of an alternative device that recognizes and judges the risk of collision on a small fishing vessel by itself regardless of the opponent's whistle or VHF call. Since the existing collision avoidance support model has been studied for small and medium-sized ships, the blocking area (Kim et al., 2019) is underestimated, and when applied to small fishing boats as it is, the two ships can be situated in a very close condition. Therefore, it is necessary to establish a collisionavoidance model for small fishing vessels by understanding the differences in handling characteristics with small and medium-sized vessels.

In this study, the collision avoidance algorithm is established as follows by considering the navigational characteristics (Matsumoto, 2017) obtained from the experience of small fishing boats at sea. By referring to the results of TABLE 1, the 
collision risk area of a small vessel is set as a circle with a radius of 0.3 miles, and the evacuation angle athat can avoid collision with the other vessel is calculated by using Equations (1)-(4).

TABLE 2 and TABLE 3 correspond to a case of collision when two ships continue to proceed, and when the distances between ships approach 1 mile and 0.5 miles, the minimum starboard angle to avoid collision is indicated. In the case of a head-on situation in TABLE 2, the two ships have a mutual obligation to avoid, but the avoidance angle was calculated assuming the avoidance collision action of only the own ship, and the same assumption was applied in the case of crossing in TABLE 3. In case of a head-on situation, the true course of the small ship is 000 degrees, the true course of the other ship is 180 degrees, and in case of crossing, the true course of the small ship is 000 degrees, and the true course of the other ship is 270 degrees. In the case of overtaking, the result is omitted because small fishing boats that are generally overtaking are considered to be aware of the overtaken vessel.

Table 2: collision avoidance angle of head-on situations (unit: degree). The upper cell in each case corresponds to the distance between the two ships is 1 nautical mile, and the lower cell is 0.5. The unit used in the table is degree, and hyphen (-) symbol represents the collision case.

\begin{tabular}{|c|c|c|c|}
\hline $\begin{array}{r}\text { Opponent } \\
\text { ship (m/s) }\end{array}$ & $\mathbf{2}$ & $\mathbf{5}$ & $\mathbf{8}$ \\
\hline \multirow{2}{*}{$\mathbf{2}$} & & & \\
\hline \multirow{2}{*}{$\mathbf{5}$} & 35 & 67 & - \\
\cline { 2 - 4 } & 74 & - & - \\
\hline \multirow{2}{*}{$\mathbf{8}$} & 25 & 35 & 47 \\
\hline & 51 & 74 & - \\
\hline
\end{tabular}

In the case of a head-on situation, the higher the speed of the own ship, the smaller the speed of the opponent ship, and the farther the ship takes an action, the collision avoidance angle becomes smaller. When the speed of the own ship is small and the speed of the opponent ship is large (for example, $2 \mathrm{~m} / \mathrm{s}$ for a small ship, $8 \mathrm{~m} / \mathrm{s}$ for the opponent ship), the own ship must avoid with a very large angle. The avoidance angle of a small ship calculated from the table tends to be somewhat large because it does not include the action of the opposing vessel, and the collision avoidance angle $\alpha$ is expected to be smaller considering the navigational relationship between two ships.

Table 3: collision avoidance angle of crossing situations (unit: degree). The upper cell in each case corresponds to the distance between the two ships is 1 nautical mile, and the lower cell is 0.5 . The unit used in the table is degree, and hyphen (-) symbol represents the collision case.

\begin{tabular}{|c|c|c|c|}
\hline $\begin{array}{r}\text { Opponent } \\
\text { ship (m/s) }\end{array}$ & 2 & 5 & 8 \\
$\begin{array}{l}\text { Own ship } \\
(\mathrm{m} / \mathrm{s})\end{array}$ & & & \\
\hline \multirow{2}{*}{2} & 35 & 75 & - \\
\cline { 2 - 4 } & 74 & - & - \\
\hline \multirow{2}{*}{5} & 22 & 35 & 51 \\
\hline \multirow{2}{*}{8} & 47 & 73 & - \\
\cline { 2 - 4 } & 20 & 25 & 34 \\
\hline
\end{tabular}


Even in the case of a crossing situation, the greater the speed of the own ship, the smaller the speed of the opponent ship, and the farther the ship takes an action, the collision avoidance angle becomes smaller. In general, the angle of avoidance is smaller in the case of crossing than in the case of head-on situation. As in the case of head-on situation, when the speed of the own ship is small and the speed of the opponent vessel is large, the own ship must evade with a very large angle.

\section{Results}

The previously described empirical model provides an avoidance angle that the ship can evade to prevent the other ship from invading into the collision risk area around the own ship by using the actual avoidance pattern of the fishing vessels. With a radius $r$ of 0.3 miles in the collision risk zone and applying the CAL method (Kim et al, 2019), the avoidance angle can be determined as well as collision avoidance in all directions, including up to 90 degrees on each side of the basis of the proceeding direction of the own ship.

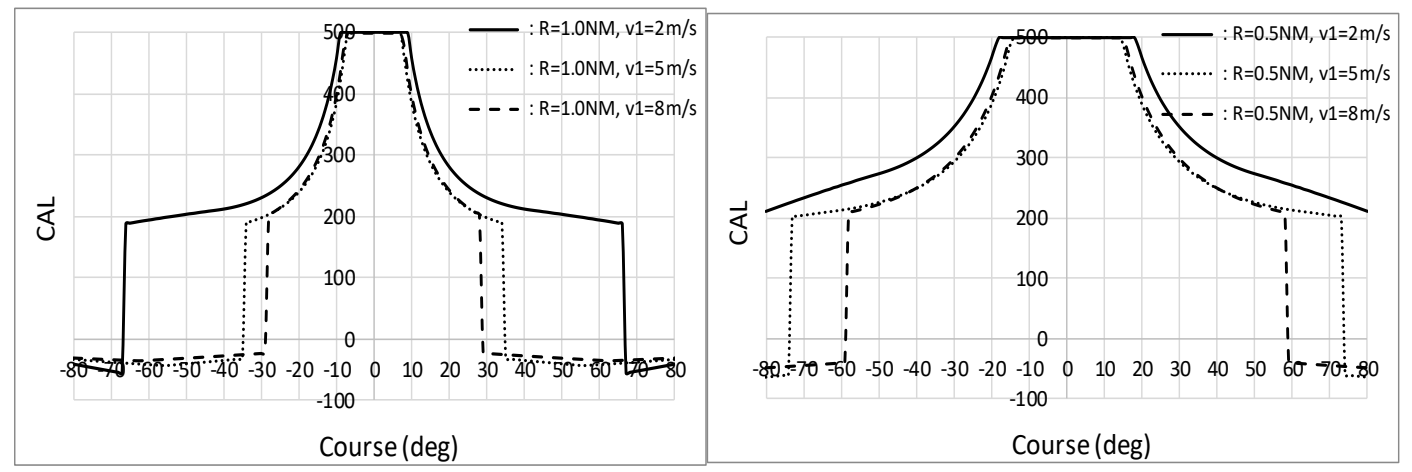

Figure 4: CAL ASSESSMENT IN HEAD-ON SITUATIONS. R=1.0NM (ABOVE FIGURE), R=0.5NM (BELOW FIGURE).

FIGURE 4 (a) represents the CAL value when the distance between own ship and the opponent ship is 1 mile. It is assumed that the own ship is a small fishing vessel moving at speeds of $2 \mathrm{~m} / \mathrm{s}, 5 \mathrm{~m} / \mathrm{s}$, and $8 \mathrm{~m} / \mathrm{s}$ and the other vessel sails at $5 \mathrm{~m} / \mathrm{s}$, and the CAL is calculated when the two vessels are close to 1 mile. The horizontal axis represents an avoidance angle of 80 degrees on each side with respect to the heading of own ship, and the vertical axis represents the maximum CAL value. In this case, CAL refers to the maximum value that can occur if the own ship continues to proceed. If the speed of the own ship is $8 \mathrm{~m} / \mathrm{s}$, the CAL value drops sharply below 200 from 29 degrees on the port and starboard sides of the own ship. Accordingly, if the own ship alters course to above 29 degrees on the starboard side by applying the starboard alteration principle of the Maritime Safety Act, the opponent ship will not be able to invade within 0.3 miles of the own ship. As the speed of the ship increases $(2 \mathrm{~m} / \mathrm{s}, 5 \mathrm{~m} / \mathrm{s}, 8 \mathrm{~m} / \mathrm{s})$, the collision avoidance angle decreases (67 degrees, 35 degrees and 29 degrees, respectively). In addition, the CAL method maximizes the visual effect compared to the conventional avoidance method so that the operator can easily understand it. FIGURE 4 (b) indicates the result of a head-on situation with a distance of 0.5 miles from the opponent ship. Since it is a short distance, the collision avoidance angle is larger than the case with a distance of 1 mile, and as the own ship's speed increases, the angle decreases. 

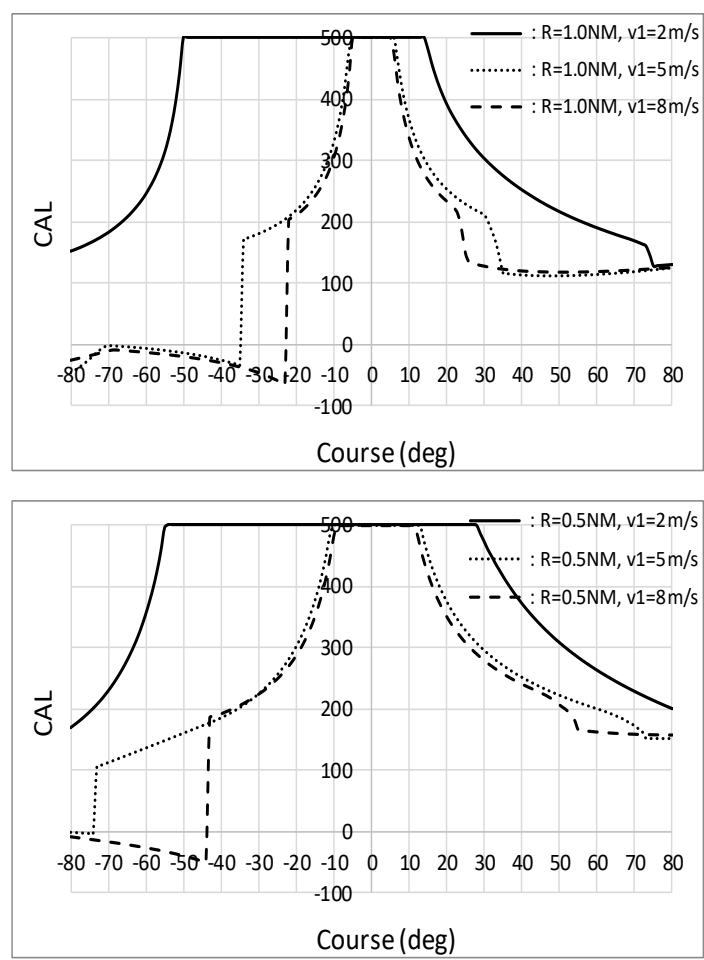

Figure 5: cal assessment in crossing situations. $\mathrm{R}=1.0 \mathrm{~nm}$ (above figure), $\mathrm{r}=0.5 \mathrm{~nm}$ (below figure).

FIGURE 5 (a) represents the CAL value for crossing situation with a distance of 1 mile from the opponent ship. The speed of the own ship is $2 \mathrm{~m} / \mathrm{s}, 5 \mathrm{~m} / \mathrm{s}$, and $8 \mathrm{~m} / \mathrm{s}$, while the speed of the opponent ship is $5 \mathrm{~m} / \mathrm{s}$. At a speed of $8 \mathrm{~m} / \mathrm{s}$, the CAL value drops sharply below 200 from 25 degrees to the starboard side and 23 degrees to the port side of the own ship. There is little risk of collision if the ship alters the course above 23 degrees on the port side. However, since the own ship is a giveway vessel, it shall change the course at least 25 degrees on the starboard side in compliance with the principle of the Maritime Safety Act, and in such cases, the opponent ship will not invade within 0.3 miles of the own ship. The greater the speed of the own ship $(2 \mathrm{~m} / \mathrm{s}, 5 \mathrm{~m} / \mathrm{s}, 8 \mathrm{~m} / \mathrm{s})$, the smaller the collision avoidance angles ( 75 degrees, 35 degrees, and 25 degrees, respectively). FIGURE 5 (b) indicates the result of crossing situation with a distance of 0.5 miles of the other ship. Since it is a collision avoidance action at close range, the angle becomes larger than when the opponent ship is 1 mile away. There are some cases where the alteration to the port side is possible to avoid collision risk, but, if possible, it is desirable to comply with the principle of the Maritime Safety Act to avoid adding confusion to the other ships. Depending on the situation, if it is inevitable to alter course to the port side, it is necessary to take measures by communicating and cooperating with the other ship.

\section{Conclusions}

According to statistics from the Korea Maritime Safety Tribunal, among the collision accidents that have occurred in the past five years, marine accidents of fishing vessels accounting for $63 \%$ of the total, which is the largest portion (KMST, 2019). This was largely due to operational characteristics such as poor working conditions of fishing boats, accumulated fatigue caused by the lack of duty personnel, and lack of attention to safety. In addition, since about 95\% of collision accidents occurred due to failure in recognition or judgment, a device is needed to detect a ship approaching a collision course by hearing and vision and to enable operators of small fishing boats to respond quickly without panic.

In this study, we considered a collision avoidance model for small fishing boats that cause most of the collision accidents, where even unskilled operators can identify the possibility of collision with other ships and provide collision avoidance course to prevent human error. In other words, we proposed a new model that can be applied directly to small vessels such 
as small fishing boats and inland vessels with excellent maneuverability and applied the CAL method to this model to maximize visual effects.

This model will play a major role in the prevention of human error, such as failure of recognition and failure of judgment, by evaluating the safety of navigation in the event of a collision and will relieve mental burden and error of judgment for ship operators. It is also expected to contribute to the emergence of more advanced autonomous ships or the realization of eNavigation in the future.

\section{References}

[1] Arimura N, Yamada K, Sugasawa S, Taga K, Ikegami J and Hatta I (1992). A Study on the Navigation Decision Support Display System, Ship's Research, 29(3), Research Report, 13-32.

[2] Jung CH (2014). A Study on the Requirement to the Fishing Vessel for Reducing the Collision Accidents, The Journal of the Korean Society of Marine Environment \& Safety, 20(1), 18-25. https://doi.org/10.7837/kosomes.2014.20.1.018

[3] Kijima K and Furukawa Y (2001). Design of Automatic Collision Avoidance System Using Fuzzy Inference, IFAC Proceedings, 34(7), 65-70. https://doi.org/10.1016/S1474-6670(17)35060-7

[4] Kim WO, Gang SJ, Youn DG, Bae JY and Kim CJ (2017). A Study on the Coastal Navigation Safety by Navigational Risk Assessment Model, The Journal of the Korean Society for Fisheries and Marine Sciences Education, 29(6), 16701675. https://doi.org/10.13000/JFMSE.2017.29.1.201

[5] Kim WO, Kim CJ, Youn DG and Kim DH (2017). Development of Maritime Traffic Risk Assessment System based on ECDIS, The Journal of the Korean Society for Fisheries and Marine Sciences Education, 29(6), 1670-1675. https://doi.org/10.13000/JFMSE.2017.29.6.1670

[6] Kim WO and Kim CJ (2018). Establishment of Navigational Risk Assessment Model Combining Dynamic Ship Domain and Collision Judgement Model, The Journal of the Korean Society of Marine Environment \& Safety, 24(1), 36-42. https://doi.org/10.7837/kosomes.2018.24.1.036

[7] Kim WO, Kang SJ, Kim YR and Kim CJ (2019). A Study on a Small and Medium-sized Ship's Collision Avoidance Support Model, The Journal of the Korean Society for Fisheries and Marine Sciences Education, 31(4), 1032-1039. https://doi.org/10.13000/JFMSE.2019.8.31.4.1031

[8] Korean Maritime Safety Tribunal (2019). Statistical annual reports from 2014 to 2018, Status of marine accidents' causes as per types and years, 43-48. https://www.kmst.go.kr/kmst/statistics/annualReport/selectAnnualReportList.do.

[9] Matsumoto H (2017). A Study on Effective Uses of a Simplified AIS on Board a Ship, Doctoral Thesis, Kobe University, 142.

[10] Son NS, Kim SY and Gong IY (2009). Study on the Estimation of Collision Risk of Ship in Ship Handling Simulator using Fuzzy Algorithm and Environmental Stress Model, Journal of Navigation and Port Research, 33(1), 43-50. https://doi.org/10.5394/KINPR.2009.33.1.043 